\title{
La influencia del WhatsApp en emisoras de radio análoga*
}

\author{
Camilo Giraldo Giraldo** \\ Fabio Andrés Cardona Cifuentes***
}

Recibido: 2017-10-30 Enviado a pares: 2017-11-06

Aprobado por pares: 2017-12-16 • Aceptado: 2018-02-25

DOI: 10.22395/angr.v16n32a7

\begin{abstract}
Resumen
El objetivo del artículo es determinar las características del uso y el impacto del WhatsApp en procesos radiales de emisoras análogas de Manizales (Colombia). Como instrumento para la metodología descriptiva y cuantitativa que siguió esta investigación, se conformó una muestra con 58 participantes (directores, productores y realizadores) adscritos a 45 programas radiales de diez emisoras análogas de Manizales. Se aplicó una encuesta con preguntas cerradas y abiertas, y una entrevista semiestructurada para probar la hipótesis. Entre los principales resultados se encontró que, a diario, el 74\% de los participantes usa WhatsApp para la producción, y un $83 \%$, para interactuar con los oyentes durante la realización del programa. La interacción por teléfono, cartas y correo electrónico es desplazada por la interacción a través de redes sociales digitales y mediante los textos, las llamadas y las notas de voz del WhatsApp. Se concluye que el WhatsApp ya se instaló como instrumento de trabajo en los procesos de producción y realización radial y que, en alguna medida, empieza a desplazar el uso de la grabadora reportera. Además de esta aplicación digital, las redes sociales transformaron la manera de producir y realizar la programación radial y, sobre todo, la forma en que participan los oyentes.
\end{abstract}

Palabras clave: radiodifusión; ciberradio; WhatsApp; emisoras análogas; nuevas prácticas radiofónicas; radio en internet; oyentes activos.

Artículo derivado del proyecto de investigación La escritura por chat especialmente por WhatsApp, inscrito en el Grupo Investigaciones de la Comunicación (categoría A2 en Colciencias) de la Universidad de Manizales (Colombia).

* Magíster en Filosofía. Profesional en Comunicación para Radio y Televisión. Profesional en Filosofía y Letras. Profesor e investigador de la Universidad de Manizales (Colombia); adscrito al Grupo Investigaciones de la Comunicación. cgiraldo@umanizales.edu.co. Orcid: http://orcid.org/0000-0001-6605-5360

... Magíster en Ciencias Sociales. Profesional en Comunicación para Radio y Televisión. Profesor e investigador de la Universidad de Manizales (Colombia); adscrito al Grupo Investigaciones de la Comunicación. fabioandrescardona@ hotmail.com Orcid: https://orcid.org/0000-0002-9839-6335 


\title{
The Influence of WhatsApp on Analog Radio Stations
}

\begin{abstract}
This article aims to determine the characteristics of use and impact of WhatsApp in radial processes of analogue stations in Manizales (Colombia). As an instrument for the descriptive and quantitative methodology followed by this research, a sample was formed with 58 participants (directors, producers, and directors) assigned to 45 radio programs of 10 analogue stations in Manizales. A survey with closed and open questions was applied, as well as a semi-structured interview to test the hypothesis. Among the main results it was found that, on a daily basis, $74 \%$ of the participants use WhatsApp for production, and $83 \%$ use it to interact with the listeners during the program. Interaction by telephone, letters, and email is ousted by interaction through digital social networks, as well as through texts, calls and voice notes in WhatsApp. It is concluded that WhatsApp has already been installed as a working tool in the radio production processes, and that it is beginning to displace the use of the reporter recorder to some extent. In addition to this digital application, social networks transformed the way of producing and performing radio programming, and above all, the way in which listeners participate.
\end{abstract}

Keywords: Broadcasting; cyberradio; Whatsapp; analogue stations; new radio practices; Internet radio; active listeners.

\section{A influência do WhatsApp em emissoras de rádio análoga}

\begin{abstract}
Resumo
O objetivo deste artigo é determinar as características do uso e o impacto do WhatsApp em processos radiais de emissoras análogas de Manizales (Colômbia). Como instrumento para a metodologia descritiva e quantitativa que esta pesquisa seguiu, foi conformada uma amostra com 58 participantes (diretores, produtores e realizadores) vinculados a 45 programas de rádio de dez emissoras análogas de Manizales. Foi aplicado um questionário com perguntas fechadas e abertas, e uma entrevista semiestruturada para provar a hipótese. Entre os principais resultados, constatou-se que, diariamente, $74 \%$ dos participantes usam o WhatsApp para a produção e $83 \%$ para a interação com os ouvintes durante a realização do programa. A interação por telefone, cartas ou e-mail é substituída pela interação por meio das redes sociais digitais e dos textos, ligações e áudios do WhatsApp. Conclui-se que esse aplicativo já se estabeleceu como instrumento de trabalho nos processos de produção e realização radial e que, de alguma forma, começa a tomar o lugar do gravador nas reportagens. Além desse aplicativo digital, as redes sociais transformaram a maneira de produzir e realizar a programação radial e, principalmente, a forma de participação dos ouvintes.
\end{abstract}

Palavras-chave: radiodifusão; ciberrádio; WhatsApp; emissoras análogas; novas práticas radiofônicas; rádio na internet; ouvintes ativos. 


\section{Introducción}

La radio sigue posicionada como un medio de alto consumo. Pese a la ola de comunicación por móviles, tabletas y aplicaciones de Internet, la radio mantiene una vigencia y actualización que le garantiza aún millones de usuarios. Esto, quizá, por la vocación de uso social con la que nació; unos "usos sociales que le han marcado el desarrollo y el rumbo desde sus orígenes" (González, 2005, p. 205). Además, la radiodifusión ha mantenido un papel protagónico en la "cosa pública", pues allí sus esfuerzos han sido absolutamente positivos (Brecht, 2003, p. 13).

Para la transmisión radial, desde sus inicios, es definitivo el desarrollo tecnológico de cada época; incluso, como sostiene González (2015), la radio es, además de medio de comunicación, una tecnología en sí misma, en cuya realización, según López (2005), cuenta también el cambiante estilo de vida de los usuarios igualmente inmersos en los recursos tecnológicos del momento. O sea que "La evolución de la radio hay que enmarcarla en la evolución de la sociedad" (Soengas, 2013, p. 25).

La radiofonía surgió como una exploración técnica para permitir la comunicación personal a distancia, y uno de sus antecedentes son los experimentos en la telecomunicación de la clave Morse. Este invento fue retomado por Gugliemo Marconi, a partir del cual creó la telegrafía sin hilos y envió mensajes telegráficos (Haussman, et al., 2001, p. 372; López, 2005, p. 11). En 1901, se logró la comunicación de un lado al otro lado del océano Atlántico y se popularizó este nuevo medio de comunicación en los barcos, como quedó registrado en la tragedia del Titanic (Joskowicz, 2014, p. 21). En poco tiempo, dice Barrios (2011), este medio se convirtió en una herramienta indispensable para la humanidad.

Hoy, además de la disminución del tamaño de los aparatos de recepción, es notable el avance en las formas de transmisión. Con Internet, la radio se liberó de los transmisores y de la regulación del espectro para emitir. Actualmente, con un PC, un celular o una tablet se producen y emiten contenidos desde cualquier parte del planeta; incluso, según Ortega (2015), los medios hacen seguimiento e interaccionan con los consumidores a través de aplicaciones u otros dispositivos.

Con acceso a Internet la radio no solo se escucha, sino que también se puede ver e interactuar con los realizadores de los contenidos. Así, "el oyente pasa de ser pasivo a formar parte del grupo programador de su emisora" (Pérez E Castellanos, 1998, p. 19), de tal forma que los usuarios, de acuerdo con Winocur (2007), participan en la producción de los mensajes y, en general, de la programación. "En este sentido, los teléfonos inteligentes son ya la primera puerta de entrada para esta interacción" (Ortega et al., 2015, p. 629).

En el ciberespacio la radio representa el ideal de la comunicación colectiva, "una comunicación en grado potencialmente ilimitado y tendencialmente simultáneo" (López, 1989). Internet ofrece diversas posibilidades de presentar o emitir y potencia el medio radiofónico que sigue redefiniéndose y reinventándose (Faus, 2001, p. 16). Y al decir de Muerza y Almoedo (2015), con el uso de las redes sociales de Internet la radio se redefine 
no solo en su producción sino también en la manera en que se comunica con los usuarios; productores y oyentes pueden conversar, en cualquier momento: antes, durante o después de las emisiones.

Para Cebrián (2009) más que la radio ubicada en Internet, se trata de un nuevo género, ciber-radio, que no es solo una "redifusión por Internet, sino que integra los componentes de esta como algo propio y los transforma para convertirlos en algo diferente" (p. 14). Y al decir de González (2009), "Se da paso a un modelo de autoservicio virtual para una audiencia fragmentada donde se propone un nuevo escenario comunicativo de estructuras multimedia" (p. 46).

Así, "el proceso comunicativo en la radio no solo tiene que ver con lo que se emite, sino con el modo en que las audiencias asumen, interpretan o reelaboran lo emitido (El'Gazi, s. f., p. 19; Winocur, 2007). De hecho, por su participación, el rol del usuario de radio deviene hoy en "prosumidor" (Islas, 2008), término de Toffler (1980), para señalar "la participación del cliente en el proceso de producción" (p. 176), como ocurre ahora en la radio, por ejemplo, en la que existe "una intervención mucho mayor del consumidor en la producción. En un mundo así se desvanecen las distinciones entre productor y consumidor" (Toffler, 1980, p. 177), como ocurre ya con algunas emisoras online.

Ahora, el marco teórico de la radio alude a los trabajos de Cebrián (2001), Merayo (2000), Ortiz $(2014,1995)$ y McQuail $(2000)$. Teóricamente, la comunicación en radio se inscribe en la perspectiva tradicional que considera la comunicación colectiva con las funciones básicas de informar, entretener y persuadir (Moreno, 2005). Algunos autores agregan la función de formar (Merayo, 2000), aunque se considere que informar, formar, entretener y persuadir no son, para emisores y receptores, funciones que aparezcan puras en la programación radiofónica (Merayo, 2000; Moreno, 2005).

Haye (1995) expone que la naturaleza radial tiene cuatro componentes que estructuran su propia gramática: palabras, sonidos, música y silencios, pero son las palabras las que tienen mayor presencia. Y tales expresiones se llevan a la radio a través de los géneros periodísticos que cumplen diversas funciones: "para responder y satisfacer a las necesidades sociales y su evolución está muy ligada al ritmo de las demandas sociales y de los objetivos de la misma profesión periodística" (Martínez \& Herrera, 2005, p. 63).

Bajo este contexto, el desarrollo de los contenidos en la programación de la radio ha concretado una clasificación teórica, aún vigente, de los modelos de programación; es una estructura condicionada por las formas expresivas de la radiofonía (Ortiz y Volpini, 1995, p.17). Estos modelos' son: generalista, especializada, híbrida o mixta (Costa, Moreno \& Amoedo, 2012; Merayo, 2000; Moreno, 2005), clasificación que tiene relación directa con

\footnotetext{
El modelo de programación Generalista es conocido como convencional o total: ofrecen variedad de música, noticias, magazines, espacios culturales, deportivos de opinión. El modelo especializado también aplica varios géneros periodísticos para dos opciones de programación: temática; por ejemplo una emisora de solo futbol, hace uso de todas las formas comunicativas, y radiofórmula, que consiste en una programación repetitiva bajo una misma estructura, que normalmente se repite automática. Finalmente, el modelo de programación mixta o híbrida combina estrategias propias del modelo Generalista con espacios al estilo del modelo radiofórmula.
} 
la manera en que se busca más conexión con el usuario y con la forma en que se realiza el producto radial, razón por la cual es asunto pertinente para este estudio.

Ahora bien, los cambios sociales, económicos y culturales implican transformaciones en la radio. Por eso, las emisoras,

In addition to being a good place to publish content, social media can be used for communicating with listeners. A radio station can choose which contacting channels they want to offer for their listeners on the basis of what kinds of people their listener base consists of (Karttunen, 2017, p. 43).

O sea, los canales de comunicación definen el tipo de audiencia y, a su vez, "La audiencia de radio siempre ha respondido de forma activa a los requerimientos de su emisora; además, se convierte en generadora de ideas, de contenidos y de conversación (Costa et al., 2012, p. 175).

Las emisoras deben, entonces, conectar a sus oyentes a través de los medios que estos usen: "Stations should find out which social media platforms their target audience is using and publish there the kind of content that the platform best suits for" (Karttunen, 2017, p. 49). Esto es, mantener vínculos a través de los recursos tecnológicos, cuyo uso se generalice en los usuarios. En ese sentido,

WhatsApp refuerza todo esto y se salta los intermediarios, además permite enviar contenidos que luego son utilizados en los programas. La radio es el medio que manda en la utilización de WhatsApp, que también comienza ahora a ser utilizada por la televisión y los periódicos, por lo que habrá que ver qué depara el futuro a esta nueva relación de periodismo-whatsApp" (Bloggin-Zenith, 2014, p. 2).

Es más, la incursión del chat y, particularmente, del WhatsApp como herramienta de trabajo para productores y realizadores en radio, es ya una práctica necesaria. "La comunicación ahora es más ágil, rápida e inmediata que en épocas anteriores, cuando se utilizaban otros canales para la participación de la audiencia como el teléfono o la correspondencia electrónica o tradicional" (Muerza \& Amoedo, 2015, p. 277). Esto, no solo para generar una producción a tono con los tiempos, sino también para mantener la participación con los usuarios y facilitar "un contacto e intercambio provisional entre los roles de emisor y receptor, y hacer posible que los oyentes intervengan en el contenido de las emisiones" (Herrera, 2005, p. 294).

Así, pues, programar en radio consiste en "idear, realizar y presentar contenidos que brinden un servicio a la audiencia acorde con los principios editoriales de la empresa, los recursos humanos y técnicos de los que dispone y los parámetros del mercado en el que se emite" (Moreno, 2005, p. 67). A partir de tal enfoque, se asume aquí, siguiendo a Ortiz y Marchamalo (1996), que la programación contempla los procesos de producción (preparación del programa) y realización (es decir, emisión), sobre los cuales este trabajo realiza la observación del uso del WhatsApp.

Entonces, ¿cómo es el proceso actual de producción y realización de programas de radio?, ¿es necesario o secundario el uso del WhatsApp en la producción y en la realiza- 
ción?, ¿es mayor la participación de la audiencia a través de las nuevas tecnologías como WhatsApp?

De estos interrogantes emergió la hipótesis de esta investigación: en las emisoras análogas ${ }^{2}$ el uso del WhatsApp ya tiene notable influencia en la gestión de la producción y la realización del programa de radio, pero no para mantener comunicación con la audiencia en la emisión o luego de ella. Se apuesta aquí que aún el teléfono, el correo electrónico o las cartas son las estrategias principales con las que las emisoras análogas vinculan a los oyentes.

Sobre el asunto de este estudio, son escasos los trabajos que anteceden en su ámbito global y local. Por ejemplo, Karttunen (2017) encontró que el uso del WhatsApp en la radio con el propósito de conectar con la audiencia es aún limitado; además, es una aplicación que tiende a confundirse con una red social:

Defining whether a service is a social media service is not always obvious. Sometimes a service may have some characteristics of social media, but not enough to make it fall into the social media category. For instance, WhatsApp, which some radio stations use to communicate with their listeners, is sometimes defined as a social media service. WhatsApp defines itself as a cross platform messaging application, whose functionality extends into voice and video calls and media sharing. WhatsApp is used to communicate only with a selected number of people such as in email, which is not a social media platform (Karttunen, 2017, p. 14).

En España, se encuentran trabajos que analizan el uso de redes sociales, pero no, específicamente, del uso del WhatsApp en las emisoras análogas. Hay una mención al respecto en Bloggin (2014) en la que se afirma que en España "la radio es el medio que más utiliza WhatsApp, ya que permite conseguir nuevos contenidos, así como relacionarse con el público. Tiene mucho éxito, sobre todo, en el caso del periodismo deportivo" (p. 1). Según estudio de la Fundación Telefónica, en 2012 las "aplicaciones como WhatsApp, además, permiten enviar no solo textos sino fotografías y vídeos y participar abierta y directamente con numerosos programas" (Bloggin, 2014, p. 2).

En otro trabajo, López (2017) halló que Onda Cero y COPE, emisoras generalistas de España, mantienen la comunicación con sus oyentes a través de las dos plataformas más relevantes: Twitter y Facebook, pero no se refiere al uso del WhatsApp en relación con los oyentes. Y Ramos $(2013,2014)$ halló que en la cadena radial SER, Twitter y Facebook son indispensables para la vinculación con la audiencia; evidenció que es Twitter la red que más uso tiene: "de las 270 actualizaciones efectuadas en sus perfiles sociales un $81 \%$ se realizaron en Twitter, mientras solo un 19\% en Facebook [...] Twitter ha adquirido una mayor consideración periodística, quedando el papel principal de Facebook relegado a una red de amistad" (Ramos, 2013, p. 7). Tampoco se alude al uso del WhatsApp para incrementar participación de los usuarios.

La mayoría de las emisoras que participaron en este estudio tienen también su versión digital; sin embargo, se apuntó a observar la dinámica del WhatsApp en la emisora tradicional o análoga. 
El estudio de Ortiz (2014) sobre las características de las emisoras comunitarias y asociativas de España y Francia no da cuenta de la intervención del WhatsApp en la producción y realización radial. Y en Colombia no se registran estudios en las emisoras análogas que se ocupen del WhatsApp en la radio; este hecho, para la presente investigación, constituye novedad y oportunidad de animar estudios relacionados.

Incluso, en investigaciones se ha encontrado que en Colombia la radio "es el medio sobre el que menos trabajos se han realizado" (Cuesta, 2012, p. 184; Castellanos, 2011; Valderrama, 2016). En el mismo sentido, Rojas (2009) reclama: ¿por qué no se consideran las especificidades de la radio de la misma manera como se defienden y argumentan las particularidades de la televisión? Mientras que Castrillón (2011) encontró que incluso en "las emisoras tradicionales carecen de archivos que permitan al investigador acceder a información" (p. 116). Comoquiera que sea, el objeto de estudio como lo apunta este trabajo es una veta de investigación.

En relación con este tema, existe un estudio de Valderrama (2016) sobre medios de comunicación en Colombia (1980-2009), que incluye al municipio de Manizales, y en el que se da cuenta de los contenidos, la forma de la producción y las tendencias teóricas y metodológicas de los medios, entre ellos la radio. Y Cuesta (2012) hizo una revisión de la radio latinoamericana y colombiana con énfasis en la radiofonía indígena. Ninguna de estas investigaciones ni otras de corte teórico de autores colombianos como Barrios (2011) y Barrios y Gutiérrez (2017) incluyen la mirada sobre la influencia del chat, y menos del WhatsApp, en los procesos radiales.

Por lo anterior, el presente trabajo se propone determinar las características del uso y el impacto del WhatsApp en programas de radio de emisoras análogas de Manizales; además, desvelar si el propósito del uso de WhatsApp en programas radiales es interactuar con los usuarios o solo como apoyo para la gestión interna del programa.

Así pues, de acuerdo con el anterior esbozo teórico y de antecedentes, este estudio se justifica porque llena el vacío sobre el asunto en la literatura científica.

\section{Metodología}

Para esta investigación empírica se adoptó el método descriptivo que implicó la observación, caracterización y recopilación sistemática de los datos, un camino que permitió recoger aspectos descriptivos y cuantitativos del uso del WhatsApp en la radio análoga. Para ello, se diseñó y aplicó una encuesta con preguntas para respuestas cerradas (SÍ, NO) y abiertas (¿Por qué? ¿Cómo?), cuya aplicación permitió la descripción y análisis del objeto de estudio. Las preguntas abiertas permitieron interactuar con cada participante, a modo de entrevista.

La población se conformó con 58 participantes adscritos a 45 programas radiales de 10 emisoras análogas de Manizales: 19 directores, 17 productores, 17 locutores, 4 periodistas, 1 programador, quienes respondieron estas preguntas: 1) ¿Usa WhatsApp en 
la producción (o preparación) del programa de radio?, 2) ¿Usa WhatsApp en la realización (o durante la emisión) del programa para interactuar con los oyentes?, 3) ¿Tiene su programa interactividad con los usuarios?, 4) ¿Cree usted que con WhatsApp ha aumentado la participación de la audiencia?, 5) ¿Ha desplazado el WhatsApp equipos o procesos de la producción y emisión de su programa?

La hipótesis de esta investigación contiene 3 enunciados: 1) en las emisoras análogas el uso del WhatsApp ya tiene notable influencia en la gestión de la producción y la realización del programa de radio, 2) pero no se usa el WhatsApp para mantener comunicación con la audiencia en la emisión o luego de ella, y 3) además, en las emisoras análogas aún el teléfono, el correo electrónico o las cartas son las estrategias que, principalmente, vinculan a los oyentes.

La organización de los datos consistió en la tabulación de las respuestas cerradas para establecer cifras y porcentajes, y el análisis de las respuestas abiertas y entrevista para la discusión e interpretación de las estadísticas.

\section{Resultados y discusión}

El estudio evidenció que en las emisoras radiales análogas de Manizales la influencia del WhatsApp alcanza procesos y modos de producción. La mayoría de los 58 participantes, el 74\%, declaró que usa el WhatsApp para la producción (gráfica 1) y un $83 \%$ dijo que lo usa diariamente para interactuar con los oyentes durante la emisión del programa (gráfica 2). Es decir, las estadísticas de estas dos gráficas confirman que se cumple el primer enunciado de la hipótesis que planteó este estudio sobre el uso generalizado del WhatsApp en la radio análoga (ver en anexo 1, consolidado de respuestas). Un hallazgo que aplica para las estaciones radiales de Manizales, pero que es una medida de lo que puede estar pasando en las demás emisoras del mismo tipo en otras ciudades del Colombia y del mundo.

La segunda declaración de la hipótesis -el uso del WhatsApp no es para mantener comunicación con la audiencia ni durante ni después del programa, sino solo como herramienta de producción o realización- no se cumple. Esto, porque 48 de los 58 encuestados, o sea el $83 \%$, declaró que el uso diario del WhatsApp es para conectar a los usuarios durante la emisión. De hecho, también se constató aquí que ya es necesario que la emisora o el programa cuenten con número de WhatsApp destinado solo para interactuar con los usuarios.

Y el tercer enunciado de la hipótesis: el teléfono, el correo electrónico y las cartas son las estrategias principales para vincular a los oyentes con las emisoras análogas no se cumple en su totalidad; es decir, como muestra la gráfica 3, se confirma que el teléfono es aún herramienta de interacción con los oyentes, pero es igualado por la comunicación a través de las redes sociales; la carta y el correo electrónico son menos usados ahora por los usuarios de las emisoras análogas de Manizales que se observaron en este trabajo. 


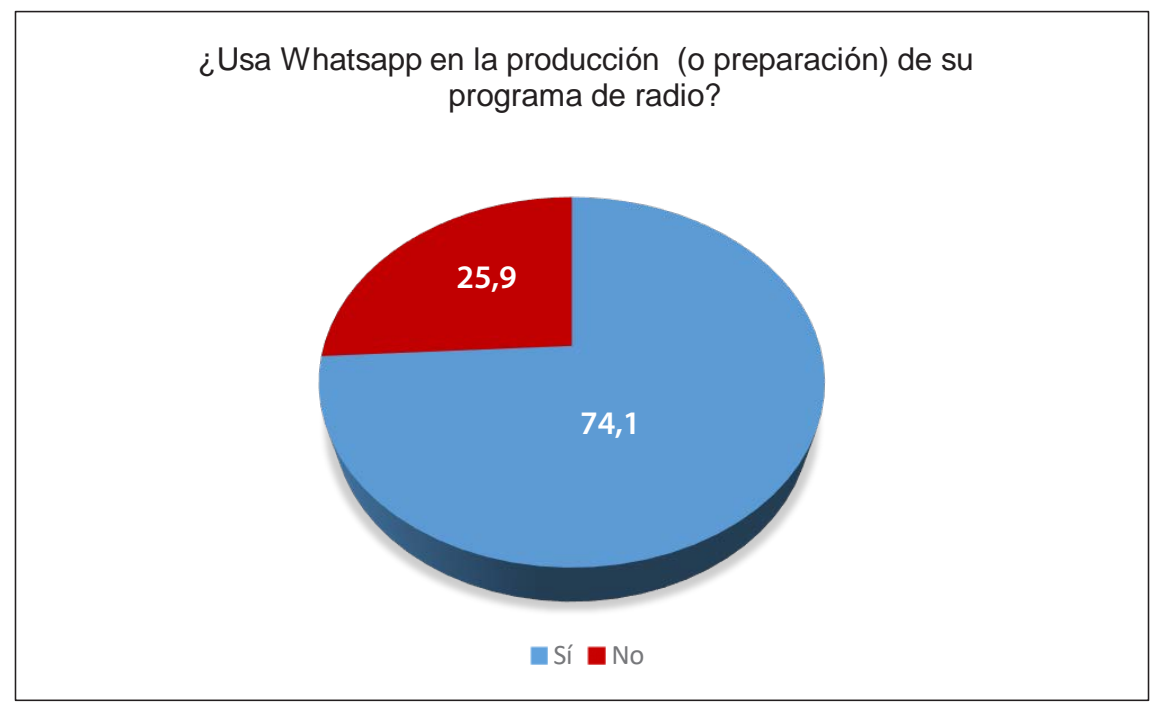

Gráfica 1. Uso del WhatsApp en la producción

Fuente: elaboración propia

\section{¿Usa Whatsapp en la realización o durante la emisión del programa para interactuar con los oyentes?}

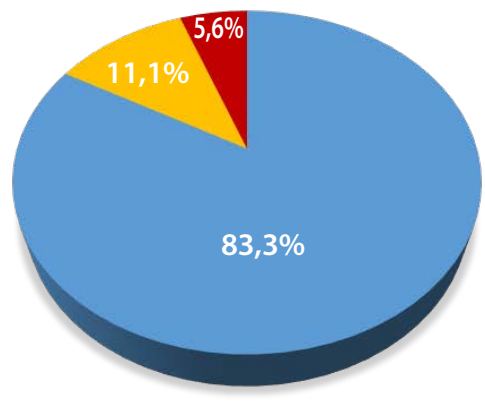

niario - Semanal

Ocasional

Gráfica 2. Uso del WhatsApp durante la realización o emisión del programa Fuente: elaboración propia

Por la vía del teléfono, existen programas cuya esencia es el diálogo con usuarios durante toda la emisión, como el caso de "Negociando" (La Voz de los Andes, 1.390 A. M.), espacio radial que ayuda a comprar y vender toda clase de objetos y servicios. Sin embargo, también disminuye la llamada al fijo, ya que "los oyentes envían notas de voz que sacamos al aire. Con WhatsApp la gente ya no llama como antes" (participante di- 
rector). Y en otros programas del mismo corte, también empieza a disminuir la llamada al teléfono fijo: "Porque vamos leyendo mensajes o reproduciendo notas de voz que nos envían mientras realizamos el programa" (participante realizador).

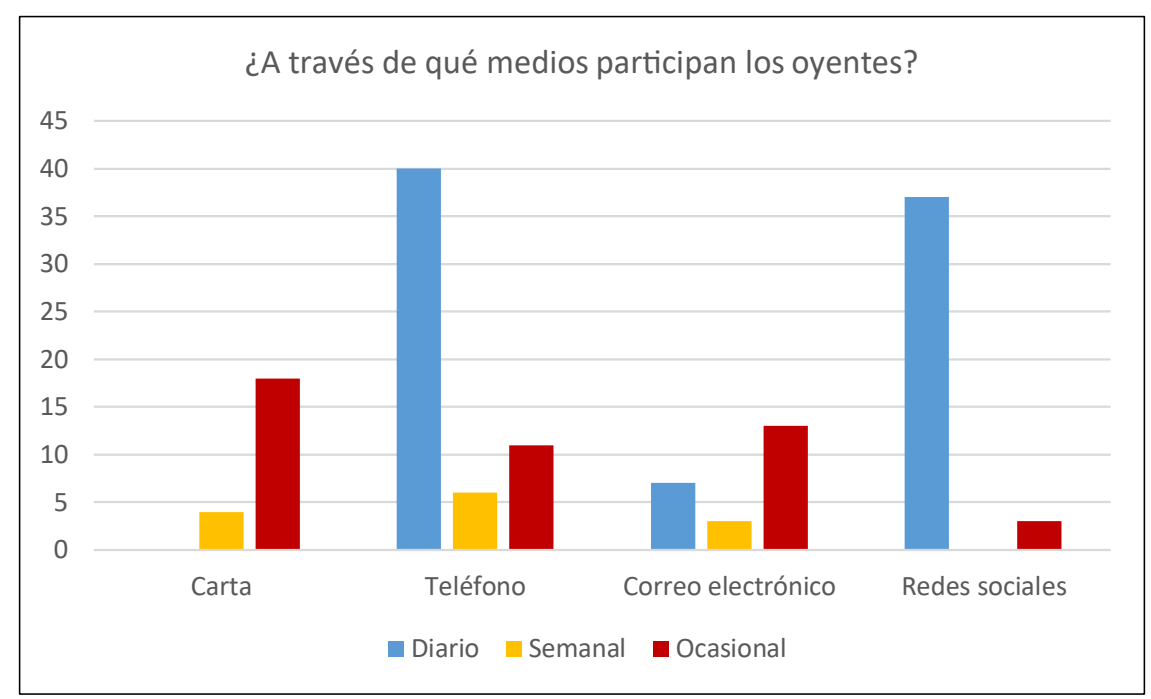

Gráfica 3. Medios a través de los que participan los oyentes Fuente: elaboración propia

En síntesis, se evidenció que la aplicación WhatsApp apoya la producción y la realización, y constituye un canal potente de interacción entre oyentes, productores y realizadores de radio. Incluso, el WhatsApp también desarrolla funciones que, según se halló en este estudio, desplazan, por ejemplo, la grabadora-reportera y el subsiguiente proceso de bajar notas para procesar y enviar. Es decir, constituye una manera rápida de recoger y tramitar la información, para responder a la velocidad que signa hoy a medios y usuarios. O, quizá, es precisamente la vinculación de estos recursos tecnológicos el factor que, a través del tiempo, ha impuesto la celeridad a la que hoy apoyan.

Algunos de los participantes coincidieron en que WhatsApp, además de facilitar el tráfico de la información, reemplaza equipos como la reportera: "Especialmente para grabar las entrevistas, porque es un medio más rápido y cualquier persona tiene un celular a la mano" (participante-productor). También, "Por la inmediatez, porque es muy práctico y garantiza buena calidad del sonido al aire" (participante productor).

Por WhatsApp, además, se graban notas de voz que se comparten en segundos. Por ejemplo, en programas como "Los adoloridos" (La Voz de los Andes, 1.390 A. M.) se encontró que son permanentes los saludos y mensajes de los oyentes interesados en encontrar una pareja; usan todas las funciones del WhatsApp: envían audios, imágenes, vídeo-llamadas, textos, vídeos y emoticones. Son programas de corte popular comunes en otras latitudes, razón por la cual es de esperarse que no solo en Manizales ocurra que 
muchos programas radiales se apoyen en esta herramienta para brindar acercamiento veloz a los usuarios y con la facilidad de expresarse con palabras escritas, orales o con imágenes o a la vez con todas estas formas de expresión.

Otro de los hechos que se verifica en este estudio es la participación de los usuarios como "reporteros". A través del WhatsApp se reciben notas de voz, textos, vídeos e imágenes de acontecimientos que se convierten en noticia. "Opinan acerca de las noticias. Nos informan sobre problemas y nos envían imágenes sobre lo que está pasando en la ciudad" (participante director). Uno de los testimonios dice que "Los oyentes nos pasan por WhatsApp eventos que suceden en la ciudad y nosotros les agradecemos al aire". De igual manera, los usuarios participan en entrevistas a los invitados al programa radial a través de WhatsApp: "La gente me escribe pidiéndome que le pregunte algo al invitado que tengo en cabina" (participante realizador).

Así, pues, en la interactividad con la audiencia -que es una de las esencias de las emisoras y programas radiales- están presentes los recursos tecnológicos del momento. Esto, porque "La participación del oyente ha sido constante en la historia de la radio. Desde sus orígenes, la radio ha utilizado distintas estrategias para buscar la fidelidad de la audiencia" (Costa et al., 2012, p. 175). Y aún crece tanto el interés por la conexión permanente con la audiencia que es uno de los factores de competencia. Y tal participación, como sostienen McQuail (2000) y Haye (1995), tiene efectos en la reorganización de la producción como, al parecer, empieza con la era WhatsApp.

Aún más, la ineludible dinámica tecnológica obliga a las emisoras análogas a mantener canales virtuales de interacción con los usuarios, como también se confirma en el estudio de Muerza y Amoedo (2015), quienes encontraron que hoy día algunos medios radiales cuentan con encargados de administrar estas plataformas digitales de interacción. Hoy, "la elaboración y difusión de contenidos radiofónicos responde a nuevas dinámicas espaciotemporales de consumo que, por una parte, rompen la linealidad y unidireccionalidad de la comunicación radio-audiencia" (Barrios E Gutiérrez, 2017, p. 228), y por otra, implican cambios en los procesos de producción y realización radial.

Las emisoras análogas tienen, entonces, el reto de acoplar de manera permanente servicios de la Internet y la telemática para dar respuesta "a las solicitudes de nuevos usuarios que, a medida que avanza el tiempo, tal vez sean más exigentes en sus demandas y en la rapidez y calidad de la programación" (Prieto E Durante, 2007, p. 323). Esto, porque los sujetos adquieren nuevos hábitos y expectativas; por eso, en radio "La cuestión radica ahora en generar nuevos modelos comunicativos, un cambio de mentalidad, un desarrollo de nuevas maneras de comunicarse con la audiencia" (Cebrián, 2001, p. 216), precisamente, lo que se hace con la aplicación WhatsApp.

Este trabajo también evidenció que los programas radiales observados, además de usar el WhatsApp para traficar más información e interactuar con los oyentes, usan este dispositivo como estrategia para auto-publicitarse "Porque el WhatsApp es un medio de 
difusión del programa y permite recordarles a los oyentes que nos escuchen" (participante realizador).

Y otra actividad que apoya el WhatsApp con sus múltiples funciones es la de permitir la creación de grupos de periodistas que se colaboran entre sí con la información oportuna, hecho que facilita aún más el ejercicio profesional, "Porque recibo información de los grupos de periodistas que hay en WhatsApp".

WhatsApp es, pues, una aplicación cuyo uso se generalizó en personas de toda edad y estrato, en toda empresa o negocio y que, por tanto, para la radio "Es una herramienta para tener un excelente contacto e interacción inmediatas, y además, se ha vuelto muy masiva entre nuestro público" (participante director). La convergencia de recursos tecnológicos, como la aplicación WhatsApp, en la industria radial transforma sus procesos, el diseño de contenidos y redefine las profesiones. Por eso, se discute por ejemplo, como lo hacen Salaverría y García (2008), que con la versatilidad de funciones tecnológicas "Los periodistas se ven igualmente sometidos a esta espiral de la convergencia, ya que tienden a acumular labores profesionales -redacción, edición, documentación, fotografía, grabación- que antes eran coto privado de especialistas en cada disciplina" (p. 32).

Otro de los hallazgos que permitió este estudio fue el de verificar que predomina el modelo de programación mixta con un $48 \%$, frente a un $31 \%$ de la generalista, y la especializada con el 21\%. Es decir, prevalece un modelo que mezcla géneros en los que la música se fusiona con noticias, espacios de opinión y programación de corte económico, cultural y político que se alterna con programas deportivos y de entretenimiento. La relación con los demás resultados del presente estudio es que la aplicación WhatsApp es transversal en todos los modelos.

\section{Conclusiones}

Las radio adapta tecnología para mantener su vigencia, especialmente, su conexión con la audiencia. Cada estación busca ser "imaginativa, innovadora y flexible para estar en consonancia con los cambios de cada época" (Faus, 2001, p. 2). Para ello, incorpora elementos de Internet o establece emisiones con "una presencia multimedia que aglutina todas las características de los demás medios" (González, 2009) y que Cebrián (2009) denomina ciber-radio.

Este estudio concluye que la aplicación WhatsApp ya penetró en las prácticas radiofónicas de las emisoras análogas. Todas las funciones del WhatsApp -texto, notas voz, vídeos, llamadas- ya se usan en los procesos de producción y realización radial; es indiscutible que esta aplicación permite dinamizar información de manera rápida y con calidad entre grupos de colegas colaboradores o en la interacción con los usuarios.

Así, pues, el WhatsApp ya se considera en la radio como un instrumento de trabajo para los procesos de producción y realización, y de alguna manera ya comienza a desplazar el uso de la grabadora reportera, por ejemplo. Se envían notas de voz de manera directa a un móvil del cual se toman para el proceso radiofónico, si se quiere, inmediato. 
Las redes sociales y las aplicaciones digitales como el WhatsApp constituyen ahora herramientas de trabajo para directores, productores y realizadores, y un mecanismo ineludible para la interacción con los oyentes. Por eso, hoy "nuevos modos de producción son requeridos por las nuevas formas de consumo e interacción de la audiencia" (Ramos, 2014, p. 2). Y es que si algo importa en la radio es la participación y la fidelidad de los oyentes (González, 2009) no solo por asuntos de su vigencia sino también de su rentabilidad.

Lo anterior porque, según García (2009), el oyente pasó de ser un agente pasivo a uno activo en la participación, y ello reinventa continuamente la forma de producir y emitir. Se debe también a que el usuario radiofónico ya no es pasivo, "Con la inclusión de sistemas y programas tecnológicos digitalizados, el oyente puede redimensionar su papel e interactuar de manera constante y directa en la producción de un espacio, llegando a sugerir contenidos" (Prieto y Durante, 2007, p. 323), que es precisamente lo que ocurre con la inclusión del WhatsApp: según los resultados de este estudio, los usuarios colaboran con la programación, con entrevistas o con información para noticias.

Sin embargo, en las emisoras análogas aún la llamada por teléfono fijo y el correo electrónico son medios que conservan alto uso para la interacción con los oyentes. Todavía son notables y numerosos los programas que los oyentes "hacen" en el momento con sus consultas o peticiones. Es una práctica radiofónica cuya agenda no se prevé, pues se construye con el insumo de la participación de la audiencia.

En síntesis, "la radio estará siempre presente en las manifestaciones humanas. Variará su uso, cambiará la tecnología para su manejo, se modificará el impacto social que produzca, se alterarán las variables económicas que determinan su entorno, pero permanecerá como una herramienta al servicio de los hombres (Pérez \& Castellanos, 1998, p. 12) o, como lo expresan Antequera y Obregón (2002), la radio permanecerá como herramienta de cambio social y fortalecimiento cultural, en medio de las ineludibles adaptaciones tecnológicas.

\section{Referencias}

ABC noticias (9 de mayo de 2010). Día mundial de las telecomunicaciones. ABC color. Recuperado de http://www.abc.com.py/edicion-impresa/suplementos/escolar/dia-mundial-de-lastelecomunicaciones-100761.html

Antequera, J. C. y Obregón, R. (2002). La radio como dinamizadora de procesos sociales y culturales. Investigación y Desarrollo, 10 (2), 46-169.

Barrios, A. (2011). De la onda a la web. Paralelo entre la radio convencional y la radio virtual. Bogotá, Colombia: Universidad Jorge Tadeo Lozano.

Barrios, A. y Gutiérrez, M. (2017). Reconfiguración de las dinámicas de la industria radiofónica colombiana en el ecosistema digital. Cuadernos.info (41), 227- 243. https://doi.org/10.7764/ cdi.41.1146

Bloggin, Z. (23 de abril de 2014). WhatsApp y radio: cuna nueva alianza lógica? Bloggin Zenith. Recuperado de http://blogginzenith.zenithmedia.es/whatsapp-y-radio-una-nueva-alianza-logica/ 
Brecht, B. (2003). La radio: ¿un descubrimiento antediluviano? Revista de Economía Política de las Tecnologías de la Información y Comunicación, 5 (2), 5-16.

Castrillón, C. (2011). Los radioaficionados como precursores de la audiencia radial colombiana, 19281940. Historia y sociedad, (20), 113-132.

Cebrián, M. (2001). La radio en la convergencia multimedia. Barcelona, España: Ed. Gedisa.

Cebrián, M. (2009). Expansión de la ciberradio. Enl@ce Revista Venezolana de Información, Tecnología y Conocimiento, 6(1), 11-23.

Costa, M., Moreno, E. y Amoedo, A. (2012). La radio generalista en la red: un nuevo modelo para la radio tradicional. Anagramas Rumbos y Sentidos de la Comunicación, 10(20), 165-180. Doi:

https://doi.org/10.22395/angr.v10n20a1 1

Cuesta, O. J. (2012). Investigaciones radiofónicas: de la radio a la radio indígena. Una revisión en Colombia y Latinoamérica. Anagramas Rumbos y Sentidos de la Comunicación, 10(20), 181-196. Doi: https://doi.org/10.22395/angr.v10n20a12

Departamento Administrativo Nacional de Estadísticas (DANE). (2016). Encuesta Consumo Cultural, 2016. Recuperado de https://www.dane.gov.co/files/investigaciones/eccultulral/presentacion_ecc_2016. pdf

El'Gazi, J. (s. f.). Que suene la radio. Bogotá, Colombia: Agencia de Estados Unidos para Desarrollo Internacional (Usaid).

Faus, A. (2001). Reinventar la radio. Revista Latinoamericana de Comunicación Chasqui, (74), 40-45. Recuperado de http://www.redalyc.org/pdf/160/16007407.pdf

García, A. (2009). Radio digital e interactiva. Revista Icono, 14(15), 133-146.

González, F. (2015). La radio y la tecnología. Revista Mexicana de Ciencias Agrícolas, (1), 205-207. Recuperado de http://www.redalyc.org/pdf/2631/263139243028.pdf

González, M. J. y Salgado C. (2009). Redes de participación e intercambios en la radio pública. Comunicar, 17(33), 45-54. Doi: https://doi.org/10.3916/c33-2009-02-004

Haye, R. (1995). Hacia una nueva radio. Buenos Aires, Argentina: Paidós.

Hausman, C., Benoit, P. y O’Donnell, L. (2001). Producción en la radio moderna. Ciudad de México, México: Itemex.

Herrera, S. (2005). El antes y el ahora de la participación de los oyentes en los programas de radio. Sphera Pública, (5), 293-307.

Islas, J. O. (2008). El prosumidor. El actor comunicativo de la sociedad de la ubicuidad. Palabra Clave, 11(1), 29-39. Recuperado de http://www.scielo.org.co/pdf/pacla/v1 ln1/v1 ln01a03.pdf

Karttunen, S. (2017). Using Social Media at a Radio Station. (Media Engineering) Helsinki Metropolia University of Applied Sciences. Recuperado de www.theseus.fi/bitstream/handle/10024/125757/ Susanna_Karttunen.pdf?sequence $=1$

López, A. (27 de enero de 2017). ¿Qué papel juegan las Redes Sociales en el día a día de las emisoras de radio? Pronoticias. Recuperado de http://prnoticias.com/internet-y-redes-sociales/redessociales/20159890-redes-sociales-emisoras-radio

López, J. I. (2005). Manual urgente para radialistas apasionados. Quito, Ecuador: Gedisa. 
Martínez, M. P. y Herrera, S. (2005). Qué son los géneros radiofónicos y por qué deberían importarnos. Global Media Journal Edición Iberoamericana, 2(3), 62-70. Recuperado de http://www.redalyc.org/ articulo.oa?id $=68720307$

McQuail, D. (2000). Introducción a la teoría de la comunicación de masas. Barcelona, España: Paidós.

Merayo, A. (2000). Para entender la radio. Barcelona, España: Ed. Universidad Salamanca.

Moreno, E. (2005). Las "radios" y los modelos de programación radiofónica. Comunicación y Sociedad, 18(1), 61-111.

Muerza, A. y Amoedo, A. (2015). El uso de las redes sociales por parte de los programas deportivos nocturnos de la radio española. Radio, sound and Internet, 276-287. Recuperado de http://www.lasics. uminho.pt/ojs/index.php/cecs_ebooks/article/view/2183

Ortega, F., González, B. y Pérez, M. E. (2015). Audiencias en revolución, usos y consumos de las aplicaciones de los medios de comunicación en tabletas y teléfonos inteligentes. Revista Latina de Comunicación Social, (70), 627-651. doi: 10.4185/RLCS-2015-1063

Ortiz, M. Á. y Volpini, F. (1995). Diseño de programas de radio. Buenos Aires, Argentina: Paidós.

Ortiz, M. Á. E Marchamalo, J. (1996). Técnicas de comunicación en radio. La realización radiofónica. Barcelona, España: Paidós.

Ortiz, M. Á. (2014). La radio como medio para la comunicación alternativa y la participación del Tercer Sector en España y Francia. Comunicación y Hombre, (10), 25-36. Recuperado de http://www. redalyc.org/pdf/1294/129432541001.pdf

Pérez, G. y Castellanos, N. (1998). La radio del tercer milenio. Bogotá, Colombia: Caracol.

Ramos, F. (junio, 2013). La cadena ser en Facebook: nuevas estrategias de interacción con la audiencia. Fonseca, Journal of Communication, (6), 108-130. Recuperado de: http://revistas.usal.es/index.php/21729077/article/view/12087/12440

Ramos, F. (2014). Redes sociales y participación radiofónica: análisis de caso de Twitter y Facebook en la Cadena SER. Ámbitos, (25), 1-13. Recuperado de http://www.redalyc.org/pdf/168/16832256006.pdf

Ramos, I. E Durante E. (2007). La evolución de la radio y las implicaciones tecno-socio-culturales en la audiencia: de oyente a usuario en la recepción del mensaje. Espacio Abierto, 16(2), 313-329. Recuperado de http://www.redalyc.org/articulo.oa?id=12216208

Rodríguez, E. (201 1). Nativos digitales en la reconfiguración radiofónica. Revista Razón y Palabra, (76), 1-9.

Rojas, S. (2009). Medios de comunicación y políticas públicas: producción de conocimiento en Colombia. Comunicación y Ciudadanía, (2), 104-113.

Salaverría, R. y García, J. A. (2008). La convergencia tecnológica en los medios de comunicación: retos para el periodismo. Trípodos, (23), 31-47.

Soengas, X. (2013). Retos de la radio en los escenarios de la convergencia digital. AdComunica, (5), 23-36. doi: http://dx.doi.org/10.6035/2174-0992.2013.5.3

Toffler, A. (1980). La tercera ola. Bogotá, Colombia: Plaza y Janes Editores.

Valderrama, C. E. (2016). La investigación en medios de comunicación en Colombia (1980-2009). Nómadas, (31), 65-72. 
Winocur, R. (2007). La participación en la radio: una posibilidad negociada de ampliación del espacio público. Razón y Palabra, 12 (55), 1-14. Recuperado de http://www.redalyc.org/articulo. oa?id $=199520735007$ 
Anexo 1. Consolidado de respuestas de la encuesta

\begin{tabular}{|c|c|c|c|c|}
\hline \multirow{2}{*}{ Preguntas } & \multicolumn{4}{|c|}{ Respuestas } \\
\hline & Sí & $\%$ & No & $\%$ \\
\hline $\begin{array}{l}\text { 1. ¿Usa Whatsapp en la producción (o preparación) del programa } \\
\text { de radio? }\end{array}$ & 43 & $74 \%$ & 15 & $26 \%$ \\
\hline $\begin{array}{l}\text { 2. ¿Usa Whatsapp en la realización (o durante la emisión) del pro- } \\
\text { grama para interactuar con los oyentes? }\end{array}$ & 36 & $62 \%$ & 22 & $38 \%$ \\
\hline 3. ¿Tiene su programa interactividad con los usuarios? & 46 & $79 \%$ & 12 & $21 \%$ \\
\hline $\begin{array}{l}\text { 4. ¿Cree usted que con Whatsapp ha aumentado la participación } \\
\text { de la audiencia? }\end{array}$ & 41 & $71 \%$ & 17 & $29 \%$ \\
\hline $\begin{array}{l}\text { 5. ¿Ha desplazado el Whatsapp equipos o procesos de la produc- } \\
\text { ción y emisión de su programa? }\end{array}$ & 27 & $47 \%$ & 31 & $53 \%$ \\
\hline
\end{tabular}

Fuente: elaboración propia 